\title{
A Comparative Study of Special Education Prevalence Rates by Disability Categories Between
}

\section{Taiwan and Wisconsin}

\author{
Bert Chiang \\ Department of Special Education, University of Wisconsin Oshkosh \\ 800 Algoma Blvd. Oshkosh, WI 54901, USA \\ Tel: (920)424-2246 E-mail: chiang@uwosh.edu \\ Cheng-Fen Chang \\ Department of Special Education, National Taiwan Normal University \\ 162, HePing East Road, Section 1, Taipei, Taiwan (10644 ) \\ Tel: (02)2356-8901 E-mail: t14002@ntnu.edu.tw
}

\begin{abstract}
Using 2007-08 special education child counts data from Wisconsin Department of Public Instruction and Taiwan's Ministry of Education, this study compares prevalence rates by disability categories. Wisconsin's prevalence rate of 12.55 is found 5.75 times greater than that of Taiwan. The greatest discrepancy is revealed in the area of Speech and Language Impairment. In other Category B areas identified by the Organization for Economic Cooperation and Development report such as Learning Disabilities and Emotional Behavior Disability, Wisconsin also reports significantly higher prevalence rates. The findings were discussed in relation to different cultural, linguistic, socio-economical and philosophical perspectives and future comparability due to the implementation of Response-to-Intervention model for LD eligibility determination in the U.S.
\end{abstract}

Keywords: Autism, disability identification, emotional disturbances, epidemiology, foreign countries, incidence, learning disabilities, speech language impairment, special education 


\section{Special Education Prevalence Rates by Disability Categories Between Taiwan and Wisconsin}

Special education services in the United States are based on federal requirements specified in PL 94-142 and its ensuing reauthorizations. Each state is required to collect data on the number of children served in various special education programs by primary disability categories and reports to the Congress on an annual basis. Similarly, Taiwan's 1984 Special Education Law and its regulations required each city to report annually collected data on the number of students served in different disability categories. The purpose of this study is to analyze the 2007-08 school year data from Taiwan and the Midwestern state of Wisconsin in order to determine whether there are significant differences in the prevalence rates of the various special education categories. This original study attempts to answer the research question whether similar definitions and identification procedure between Taiwan and Wisconsin schools results in similar prevalence rates of special education students.

Despite the fact that the eligibility criteria currently applied in Taiwanese schools suggests that by and large Taiwan follows PL 94-142 regarding the definitions of disability categories and the identification and placement procedures, variations in special education prevalence rates between countries are expected (Berkson, 1993; Frankberger \& Harper, 1988; Keller, Ball, \& Hallahan, 1987). In fact, Acherbach, Verhulst, and Stutton (1987) as well as Cederbald (1988) reported relatively minor prevalence differences between countries in certain categories associated with emotional behavioral disturbance. On the other hand, Le Roy, Evans, \& Deluca (2000) found a much wider discrepancy in prevalence rates in the speech and language impairment category between European countries and the United States, because of a broader definition of this impairment in the U.S., including English as a second language.

Comparing the trends and common denominators in the prevalence rates of children with health-related disabilities among the United Kingdom, United States, Denmark, Norway, Finland, Sweden, Iceland, and Israel, Merrick and Carmeli (2003) considered the severity of disabilities as a critical factor. They suggested the use of mild, moderate and severe as categories while examining disability rates. LeRoy, Evans, and Deluca (2000) compared United States and European school-aged disability prevalence in their Organization for Economic Cooperation and Development (OECD) report. They delineated three cross-national categories of special needs education: Category A includes those involve organic disorders such as "blind and partially sighted, deaf and partially hearing, severe and profound mental handicap, and multiple handicaps” (Leroy, Evans, \& Deluca, p.2). Category B mainly includes individuals with learning disability and emotional behavioral disturbance. Category C pertains to students "whose difficulties are considered to arise primarily from socio-economic, cultural, and/or linguistic factors” (Leroy, Evans, \& Deluca, p.2). A major finding of their comparison of school-aged disability prevalence of the 23 OECD member countries indicates no differences among countries on the common core of disability classifications with the exception of a higher rate of speech and language impairment in the United States. Based on the three categories delineated by LeRoy, Evans, and Deluca, the OECD (2007) published a comprehensive book entitled "Students with Disabilities, Learning 
Difficulties and Disadvantages" analyzing policies, statistics, and trend indicators and established an internationally comparative framework on special education. In fact, the essence of the three categories is encapsulated by the three words Disabilities, Difficulties, and Disadvantages (DDD) in the book title.

\section{Method}

The special education demographic data from Wisconsin were taken from the Wisconsin Department of Public Instruction website, Federal Data Collection Statewide Reports. http://dpi.wi.gov/sped/cc-10-1-07.html. Specifically, the Wisconsin Child Count of children eligible for IDEA funding for 2007-2008 was organized by age groups and primary disability, reflecting child counts on the third day of September 2007. The age groups include 3-6, 6-11,12-17, and 18-21. The primary disability groups include Cognitive Disability, Hearing Impairment, Speech or Language Impairment, Visual Impairment, Emotional Behavioral Disability, Orthopedic Impairment, Other Health Impairment, Specific Learning Disability, Deaf-Blind, Autism, Traumatic Brain Injury, Significant Developmental Delay (Ages 3-5 Only). In order to calculate the prevalence rates, the total public school enrollment of 874,633 and total private school enrollment of 133,606 were obtained from Wisconsin Department of Public Instruction’s demographic data webpage : http://dpi.wi.gov/sig/dm-demographics.html.

The special education data from Taiwan were gathered from the Ministry of Education's Special Education Transmit Net webpage: http://www.set.edu.tw/frame.asp. The 2007-2008 school year data was updated on May 28, 2008. The data was organized by Preschool, Elementary Schools, Junior High Schools, and High Schools and Vocational Schools. The primary disability categories include Mental Retardation, Visual Impairment, Hearing Impairment, Speech or Language Impairment, Orthopedic Impairment, Health Impairment, Serious Emotional Behavioral Disability, Specific Learning Disability, Multiple Disability, Autism, Significant Developmental Delay, and Other Obvious Disability.

\section{Results and Discussion}

This study chose to compare the special education prevalence rates between Taiwan and the state of Wisconsin because the first author has been a special education teacher educator in Wisconsin for the past 30 years and spent his recent sabbatical at Taiwan National Normal University last November. As shown in Table 1, Wisconsin's overall number of special education students and prevalence rate of $12.55 \%$ in $2007-08$ school year is 5.75 times greater than that of Taiwan. In fact, the only category in which Taiwan has a higher prevalence rate is in orthopedic disorder (.15 versus .12). Taiwan's special education services do not include two categories that Wisconsin has applied: Deaf and Blind, and Traumatic Brain Disorder; while Wisconsin's child counts do not include two categories used by Taiwan's system: Multiple Disabilities, and Other Obvious Disabilities. Consistent with the findings by Le Roy, Evans, \& Deluca (2000), the greatest discrepancy is indicated in the area of Speech and Language with the Wisconsin rate of 3.21\% being nearly 80 times higher than that of Taiwan's rate $(.04 \%)$. In categories of LD and EBD, Wisconsin also has a significantly higher rate than that of Taiwan. In both categories, Wisconsin's rates are approximately 8 times greater that of Taiwan. 
Therefore, this finding does not lend support to the low international discrepancy in EBD prevalence suggested by Acherbach, Verhulst, and Stutton (1987) as well as Cederbald (1988). Tzeng (2007) identified several culture or society-specific factors accounting for the relatively low LD prevalence rate in Taiwan, including Chinese orthography, general education teachers' compliance with referral procedures and parental attitudes, and identification procedures. It is particularly important to note that Tzeng suggested that the value of schooling as indicated by the readily available after-school tutoring programs in Taiwan may have contributed to the relatively less need for LD services as the only viable remedial support for students who are at risk for academic failures. Interestingly the emerging Response To Intervention (RTI) model in the U.S. with a more systematic after-school tutoring as the second-tier services for students not responding adequately to universal core instruction may be considered parallel to the privately funded tutoring programs in Taiwan. Therefore, future research investigating the comparative prevalence rates of LD between Taiwan and the United States may need to focus on the impact of the RTI model in the U.S. as well as that of private tutoring services in Taiwan.

Table 1. Comparison of 2007-08 special education prevalence rates by disability categories between Taiwan and Wisconsin

\begin{tabular}{|c|c|c|c|c|}
\hline \multirow[b]{2}{*}{ Disability Categories } & \multicolumn{2}{|l|}{ Taiwan } & \multicolumn{2}{|c|}{ Wisconsin } \\
\hline & Students & Rate & Students & Rate \\
\hline Mental Retardation & 28,829 & 0.75 & 10,434 & 1.03 \\
\hline Hearing Impairment & 3,816 & 0.09 & 1,657 & 0.16 \\
\hline Speech Language & 8,129 & 0.04 & 32,365 & 3.21 \\
\hline Visual Impairment & 1,649 & 0.04 & 3,135 & 0.31 \\
\hline Emotional/Behavior Disorder & 6,930 & 0.19 & 15,074 & 1.50 \\
\hline Orthopedic Disorder & 6,174 & 0.15 & 1,166 & 0.12 \\
\hline Other Health Impairment & 3,726 & 0.09 & 15,125 & 1.50 \\
\hline Learning Disabilities & 18,336 & 0.50 & 40,724 & 4.04 \\
\hline Deaf--Blind & ---- & ----- & 4 & 0.0004 \\
\hline Autism & 6,358 & 0.14 & 6,217 & 0.62 \\
\hline Traumatic Brain Disorder & ---- & ----- & 406 & 0.04 \\
\hline Multiple Disabilities & 7,339 & 0.09 & ----- & ----- \\
\hline $\begin{array}{l}\text { Significant Developmental } \\
\text { Disabilities }\end{array}$ & 8,878 & 0.21 & 2,861 & 0.28 \\
\hline Other Obvious Disabilities & 3,117 & 0.08 & ------- & ----- \\
\hline Total & 89,900 & 2.18 & 126,496 & 12.55 \\
\hline
\end{tabular}


In the category of Autism which has rapidly growing recent rates in both Wisconsin and Taiwan, the .62 prevalence rate reported in Wisconsin is about five times greater than that of Taiwan. Future research of comparing Autism prevalence rates between Taiwan and the U.S. may need to factor in children's exposure to the various environmental toxins including vaccine schedules. It is also noteworthy that the discrepancy between Autism prevalence rates between Taiwan and Wisconsin may be in part explained by the differential application of diagnostic substitutions for the high-functioning Autism cases.

Table 2. Comparison of 2007-08 special education prevalence rates by disability categories and program levels between Taiwan and Wisconsin

\begin{tabular}{|l|l|l|l|l|}
\hline Categories & \multicolumn{3}{l|}{ Taiwan } & \multicolumn{2}{l|}{ Wisconsin } \\
\hline & Elementary & Secondary & Elementary & Secondary \\
\hline Mental Retardation & .65 & .87 & .59 & 1.52 \\
\hline Hearing Impairment & .07 & .11 & .12 & .18 \\
\hline Speech Language & .07 & .02 & 3.56 & .63 \\
\hline Visual Impairment & .03 & .05 & .03 & .63 \\
\hline $\begin{array}{l}\text { Emotional Behavior } \\
\text { Disorder }\end{array}$ & .22 & .15 & .85 & 2.24 \\
\hline $\begin{array}{l}\text { Orthopedic } \\
\text { Disorder }\end{array}$ & .14 & .16 & .09 & .11 \\
\hline $\begin{array}{l}\text { Other Health } \\
\text { Impairment }\end{array}$ & .08 & .10 & 1.09 & 1.85 \\
\hline Learning Disabilities & .39 & .63 & 2.14 & 6.29 \\
\hline Autism & .18 & .11 & .54 & .57 \\
\hline $\begin{array}{l}\text { Significant } \\
\text { Developmental } \\
\text { Disabilities }\end{array}$ & .18 & --- & .02 & --- \\
\hline Total & 2.0 & 2.38 & 9.04 & 13.49 \\
\hline
\end{tabular}

Table 2 displays the child counts and prevalence rates by elementary and secondary school levels for the common categories used by both Taiwan and Wisconsin. It is important to point out that the child count data from Wisconsin uses children's age to categorize those who are age 3 through 5, 6 through 11, 12 through 17, and 18 through 21. On the other hand, data from Taiwan reported those who are in early childhood programs, elementary schools, junior high schools, and high schools. It is also important to understand that in Taiwan students attend kindergarten through sixth grade in elementary schools, followed by 3 years of junior high and 3 years of senior high while in Wisconsin children attended elementary schools through $5^{\text {th }}$ grade, followed by 3 years of middle schools and 4 years of high school. The elementary school prevalence rates in Table 2 exclude those in early childhood or age 3 to 5 because of the difficulties of obtaining reliable overall counts for early childhood or children between 3 and 5 to serve as the denominators for the prevalence rate calculation. As expected, Table 2 shows much higher prevalence rates for Speech and Language Impairment at the elementary school level than the secondary school level in both Taiwan and Wisconsin. Conversely, the 
prevalence rates of LD and EBD are significantly higher at the secondary school level than those at the elementary level. The higher rates at the secondary schools more than likely reflect the fact that very few students with LD or EBD exit from special education after their initial identification. Therefore, the counts at the secondary schools represent a cumulative count of students who have been placed in special education program over yeas.

\section{Concluding Remarks}

There are a number of sources of variation in comparing special education prevalence rates across different nations, including definitions of disability categories and unreliable or invalid data sources. Additionally, mild disabilities such as LD may not emerge in similar ways in different countries due to different cultural, linguistic, socio-economical and philosophical perspectives (Lloyd, Keller, \& Hung, 2007). However, it is interesting to point out that Wisconsin's 4\% LD prevalence rate may be brought down to a substantially lower level with the emerging application of Response-to-Intervention to replace the significant discrepancy model to determine eligibility. Based on McLaughlin's (2006) estimation that 75\% of the 6.6 million or $13 \%$ of school population that are currently served in the U.S. can be reduced to about 3.25\% with the implementation of RTI. The prevalence rates between Taiwan and Wisconsin are expected to be more comparable in coming years if this prediction comes to fruition.

\section{References}

Achenbach, T. M., Verhulst, F. C., Baron, G. D., \& Althaus, M. (1987). A comparison of syndromes derived from the Child Behavior Checklist for American and Dutch boys aged 6-11 and 12-16. Journal of Child Psychology and Psychiatry, 28, 437-453.

Berkson, G. (1993). Children with handicaps: A review of behavioral research. Hillsdale, New Jersey: Lawrence Erlbaum Associates, Publishers.

Cederblad, M. (1988). Behavioral disorders in children from different cultures. Acta Psychiatrica Scandinavica, Suppl. No. 344, 78, 85-92.

Frankenberger, W., \& Harper, J (1988). States' definitions and procedures for identifying children with mental retardation: Comparison of 1981-1982 and 1985-1986 guidelines, Mental Retardation, 26 (3), 133-136.

Keller, C. E., Ball, D. W., \& Hallahan, D. P. (1987). Questioning the defense of different numbers: A reply to Algozzine and Ysseldyke. Remedial and Special Education, 8(2), 57-59.

Lloyd, J. W., Keller, C., \& Hung, L.Y (2007). International understanding of learning disabilities. Learning Disabilities Research \& Practice, 22 (3), 159-160.

LeRoy, B. W., Evans, P., \& Deluca, M. (2000). United States and European school-aged disability prevalence: An investigative study to elaborate differences. A Report for Organization for Economic Co-operation and Development. 


\section{Al Macrothink}

International Journal of Education

ISSN 1948-5476

2009, Vol. 1, No. 1: E2

Merrick, J., \& Carmeli, E. (2003). A review on the prevalence of disabilities in children. The Internet Journal of Pediatrics and Neonatology. 3 (1).

McLaughlin, M. J. (2006). Closing the achievement gap and students with disabilities: The new meaning of a "free and appropriate public education." Unpublished manuscript.

Organization for Economic Co-operation and Development. (2007). Students with Disabilities, Learning Difficulties and Disadvantages. OECD Publishing.

Tzeng, S. J. (2007). Learning disabilities in Taiwan: A case of cultural constraints on the education of students with disabilities. Learning Disabilities Research \& Practice, 22 (3), 170-175. 